\title{
In situ real-time analysis of alloy film composition and segregation dynamics with parallel detection reflection electron energy loss spectroscopy
}

\author{
C. C. Ahn, H. Yoshino, T. Tambo, S. S. Wong, G. He, M. E. Taylor, and H. A. Atwater ${ }^{a)}$ \\ Thomas J. Watson Laboratory of Applied Physics, California Institute of Technology, Pasadena, \\ California 91125
}

(Received 15 July 1997; accepted for publication 9 September 1997)

\begin{abstract}
Real-time measurements of $\mathrm{Ge}_{x} \mathrm{Si}_{1-x} / \mathrm{Si}(001)$ composition and segregation dynamics in $\mathrm{Sn} / \mathrm{Si}(001)$ in molecular beam epitaxy are demonstrated using parallel detection reflection electron energy loss spectroscopy. Parallel detection enables quantitative acquisition of low-loss spectra in a time of $<500 \mu \mathrm{s}$ and surface composition determination in $\mathrm{Ge}_{x} \mathrm{Si}_{1-x} / \mathrm{Si}(001)$ via $\mathrm{Ge} L_{2,3}$ core loss analysis to a precision of approximately $2 \%$ in time of order $1 \mathrm{~s}$. Segregation and trapping kinetics of monolayer thickness Sn films during Si epitaxy on $\mathrm{Sn}$-covered $\mathrm{Si}(100)$ has also been studied using the Sn $M_{4,5}$ core loss. (C) 1997 American Institute of Physics.
\end{abstract}

[S0003-6951(97)03744-3]

${ }^{1}$ Reflection high energy electron diffraction (RHEED) has become the most widely used in situ structural analysis method for epitaxial growth in vacuum environments owing to the high surface sensitivity and long working distance that does not interfere with film growth. Inelastic electron scattering generally complicates quantitative RHEED measurements, but it also represents a source of valuable spectroscopic information which can be used to determine overlayer thickness, ${ }^{1,2}$ surface composition in alloy films, ${ }^{3}$ and contaminant concentration ${ }^{4}$ via quantitative measurement of core-loss intensities in reflection electron energy loss spectroscopy (REELS). Until recently, measurement of REELS spectra using a serial-detection energy loss spectrometer has required data acquisition times of tens of seconds to tens of minutes. ${ }^{5}$ However, to be useful for practical film growth rates in the $0.01-1 \mathrm{~nm} / \mathrm{s}$ range, REELS spectra should be acquired in times less than or equal to that required for growth of a monolayer (i.e., $0.1-10 \mathrm{~s}$ ). In this letter, we describe the use of a parallel-detection REELS spectrometer in high speed REELS measurements of both low-loss features $(400 \mu \mathrm{s}$ for $0-100 \mathrm{eV})$ and relatively deep core-loss intensities ( $2 \mathrm{~s}$ for $1200-1300 \mathrm{eV}$ ) during epitaxial growth of $\mathrm{Ge}_{x} \mathrm{Si}_{1-x} / \mathrm{Si}(001)$ and $\mathrm{Sn} / \mathrm{Si}(001)$.

REELS with serial data acquisition employs an analyzer that accepts only a small fraction $(\sim 0.1 \%)$ of the energy loss spectrum at a time. Faster detection using parallel data acquisition has been employed in applications other than molecular beam epitoxial (MBE) growth, such as transmission electron microscopy. ${ }^{6}$ In parallel-detection reflection electron energy loss spectroscopy (PREELS), the energy-selecting slit and detector/multichannel scaler system are replaced with optics that allow detection of the entire electron dispersion at the spectrometer exit, as depicted in Fig. 1. Quadrupole lenses magnify the dispersion to optimize coupling to a cooled $256 \times 1024$ element charge coupled device $(\mathrm{CCD})$ array detector via a phosphor-coated screen. The detector array is capable of 18 bit dynamic range at readout rates of 10-32

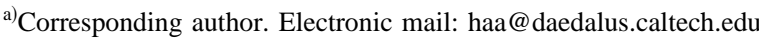

$\mathrm{ms} /$ pixel with noise levels of 1.5 counts rms/element-root scan. The overall energy resolution of the PREELS instrument is $\sim 6 \mathrm{eV}$, a limitation imposed by the RHEED gun crossover, and identical to that of serial REELS, as the external sextupole lens at the spectrometer exit nullifies any remaining second-order aberrations of the magnet. Quadrupole lenses do not possess sextupole moments, and thus do not affect the second-order focusing properties at the prism exit. The lateral spread of $30 \mathrm{keV}$ electrons inside the phosphor screen is of the order of several $\mu \mathrm{m}$, and since the pixel size of the CCD array is $19 \mu \mathrm{m}$, the spatial uncertainty of a photon generated inside the phosphor does not adversely affect energy resolution. Two pairs of electromagnetic dipoles are used to rock the incident RHEED beam before it strikes the substrate, allowing various incidence angles to be employed, while ensuring that the scattered beam is consistently aligned with the optic axis of the spectrometer.

PREELS analysis of $\mathrm{Ge}_{x} \mathrm{Si}_{1-x}$ alloys of various compositions yields $\mathrm{Ge} L_{2,3}$ core-loss intensities of comparable signal-to-noise ratio, but with acquisition times 50-500

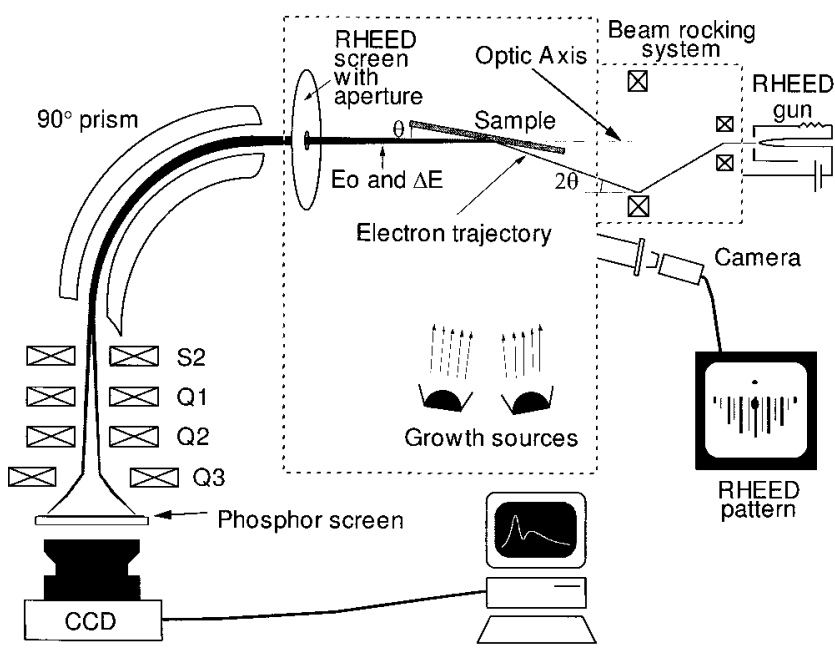

FIG. 1. Schematic of parallel-detection reflection electron energy loss spectrometer interfaced to molecular beam epitaxy system. 

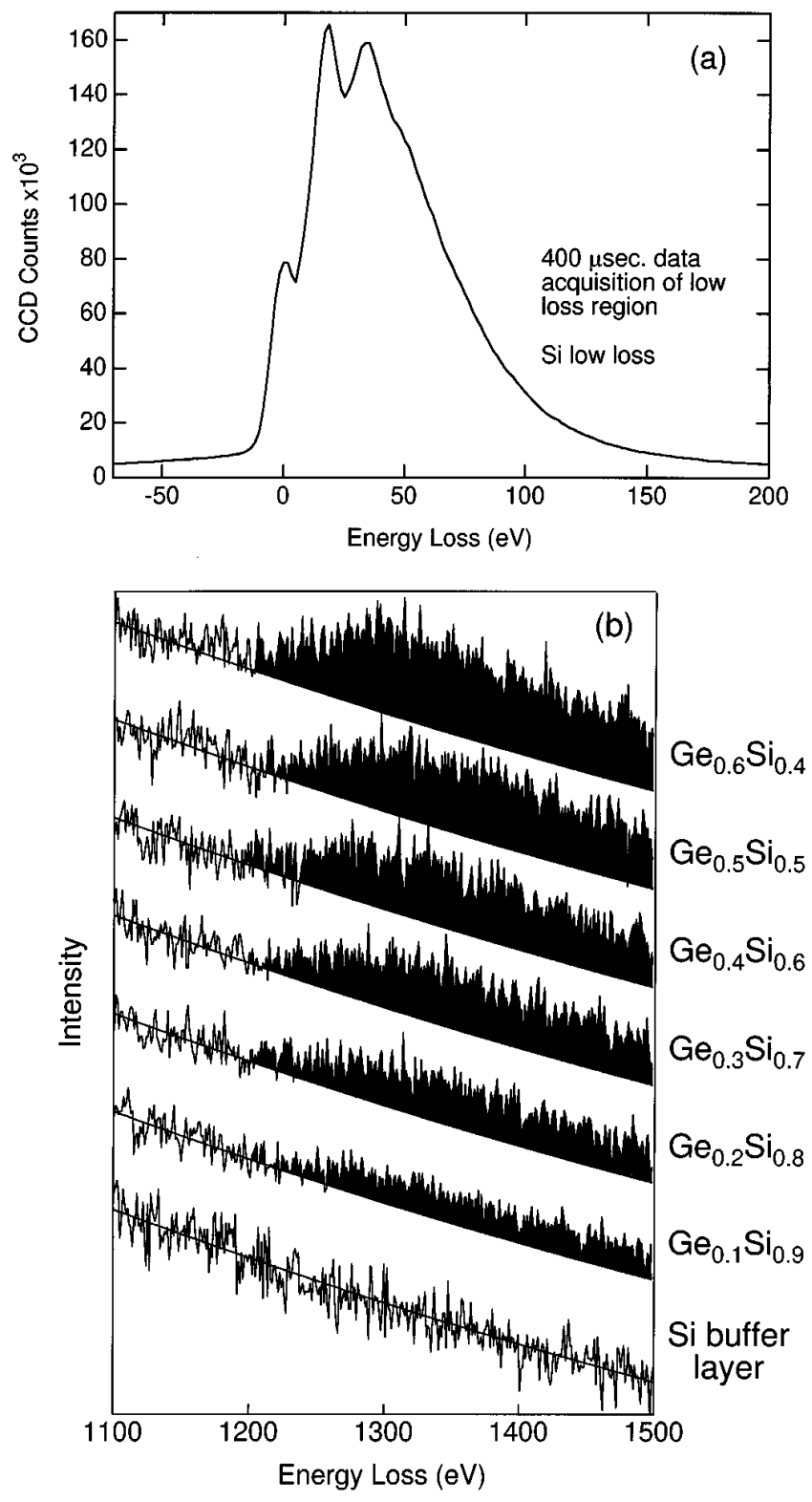

FIG. 2. Electron dispersion in the low-loss region indicating zero-loss and first and second plasmon peaks for a silicon (001) surface along [110] for $400 \mu$ s data acquisition time in (a). In (b), background-subtracted Ge $L_{2,3}$ core-loss intensity for several $\mathrm{Ge}_{x} \mathrm{Si}_{1-x}$ alloys of the heterostructure, for $2 \mathrm{~s}$ data acquisition

times shorter than with serial detection. With parallel detection, acquisition of a complete spectrum requires only seconds, even for relatively deep core losses such as Ge $L_{2,3}$.

PREELS analysis of alloy composition was performed during MBE of $\mathrm{Ge}_{x} \mathrm{Si}_{1-x}$ heterostructures grown with stepwise graded composition, with individual layer thicknesses of $30 \mathrm{~nm}$, and layer compositions ranging from $0.1<x<1$ in steps of $x=0.1$, on $\mathrm{Si}(100)$ substrates. The system base pressure was $7 \times 10^{-11}$ Torr, but rose to the low $10^{-9}$ Torr range during deposition. PREELS spectra were obtained throughout the growth, with an electron beam incidence angle of approximately $26 \mathrm{mrad}$, and a $12 \mathrm{mrad}$ collection semiangle. Bragg reflections from the (00) rod were analyzed for a $\mathrm{Ge}_{x} \mathrm{Si}_{1-x}(001) 2 \times 1$ surface along the [110] direction. Composition measurements were derived from Ge $L_{2,3}$ and $\mathrm{Si} L_{2,3}$ core-loss intensities. The low-loss spectrum in Fig. 2(a) il-

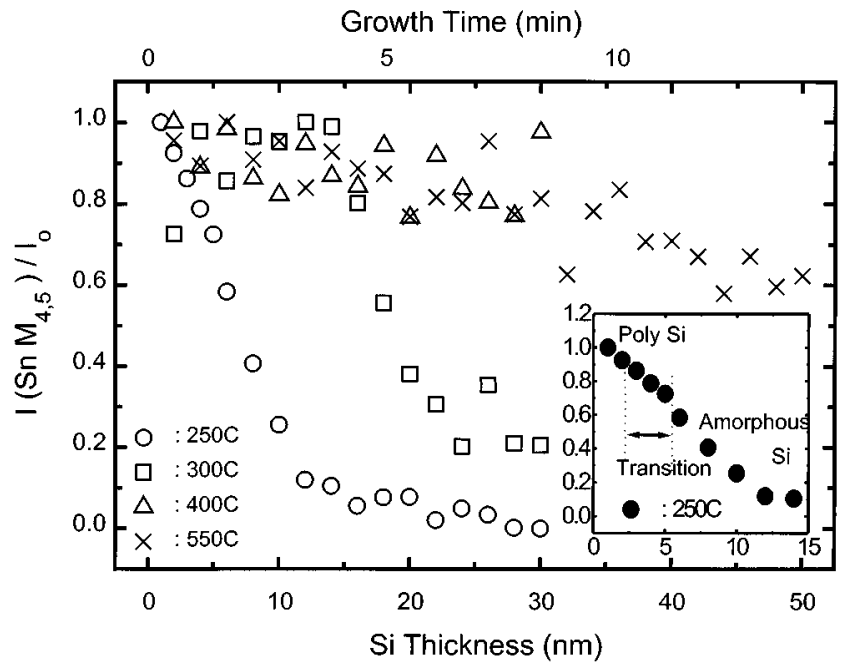

FIG. 3. Variation of normalized Sn $M_{4,5}$ core-loss intensity from $0.5-\mathrm{nm}$ thick Sn films with deposited Si thickness at $550{ }^{\circ} \mathrm{C}$ (crosses), $400{ }^{\circ} \mathrm{C}$ (triangles), $300{ }^{\circ} \mathrm{C}$ (squares), and $250{ }^{\circ} \mathrm{C}$ (circles). Inset illustrates the transition from crystal to amorphous $\mathrm{Si}$ for growth at $250^{\circ} \mathrm{C}$.

lustrates that extremely short data collection times $(<500 \mu \mathrm{s})$ can yield high signal-to-noise ratio low-loss data. Figure 2(b) shows background-subtracted Ge $L_{2,3}$ core-loss intensities for several $\mathrm{Ge}_{x} \mathrm{Si}_{1-x}$ alloys for $2 \mathrm{~s}$ data acquisitions. Despite high frequency noise, the Ge $L_{2,3}$ edge is clearly visible for a $\mathrm{Ge}_{0.1} \mathrm{Si}_{0.9}$, and since alloy composition analysis is derived from integration over a $200-400 \mathrm{eV}$ window region beyond the edge, this high frequency noise does not affect composition measurement precision. Comparison of the data in Fig. 2(b) with post-growth composition measured by $2 \mathrm{MeV} \mathrm{He}^{+}$Rutherford backscattering spectrometry shows quantitative agreement to within $2 \%$ with precision limited by the signal-to-background in Rutherford backscattering spectra.

In another set of experiments, $\mathrm{Sn}$ segregation during $\mathrm{Si}$ epitaxy on $\mathrm{Si}(001)$ was investigated. Although $\mathrm{Sn}$ segregation during $\mathrm{Si}$ epitaxy on the (001) surface has not been studied extensively, previous investigations of homoepitaxy on $\mathrm{Si}(111)$ surfaces employing $\mathrm{Sn}$ as a surfactant for epitaxial growth indicates smoother growth than for Si epitaxy without $\mathrm{Sn}$ at temperatures greater than $330^{\circ} \mathrm{C} .^{7}$ In this work, 0.5-nm-thick $\mathrm{Sn}$ layers were deposited on $\mathrm{Si}(001)$ buffer layers. Sn segregation was monitored during subsequent $\mathrm{Si}$ epitaxy at a constant growth rate of $0.05 \mathrm{~nm} / \mathrm{s}$ at temperatures of $550,500,400,300$, and $250{ }^{\circ} \mathrm{C}$. An incident electron beam angle of approximately $30 \mathrm{mrad}$ was used. The variation of normalized $\mathrm{Sn}$ coverage, as determined from the $\mathrm{Sn} M_{45}$ core loss, with Si thickness is shown in Fig. 3. At $400-500{ }^{\circ} \mathrm{C}$, the normalized $\mathrm{Sn}$ coverage decreased from 1.0 to $0.9 \mathrm{ML}$ after growth of $25 \mathrm{~nm}$ of $\mathrm{Si}$, in essentially the same manner independent of temperature. The decrease in normalized Sn intensity was interpreted to be a result of coarsening of the initially smooth $\mathrm{Sn}$ film into $\mathrm{Sn}$ islands during subsequent $\mathrm{Si}$ growth. ${ }^{8}$ Post-growth analysis by scanning Auger and optical microscopy confirmed that micron-scale $\mathrm{Sn}$ islands were present on the Si surface. During $\mathrm{Si}$ growth at $300{ }^{\circ} \mathrm{C}$, the RHEED pattern indicated the development of considerable surface roughness, and forma- 
tion of twin defects, and after $15 \mathrm{~nm}$ of $\mathrm{Si}$ growth, an epitaxial to polycrystalline transition occurred. During $\mathrm{Si}$ growth at $250{ }^{\circ} \mathrm{C}$, the surface roughened during the initial stages of growth and after 4-6 nm of growth a transition from epitaxial to amorphous film growth ensued.

Reflection electron energy loss spectroscopy enables both low-loss and core-loss spectroscopy of RHEED electrons to complement the structural information present in RHEED data. While both electrostatic ${ }^{9,10}$ and electromagnetic filters ${ }^{5}$ provide serially acquired low-loss spectra in the energy loss range of $0-50 \mathrm{eV}$, parallel data acquisition of deep core loss spectra, necessary for real time REELS analysis, has been performed using a magnetic sector. REELS has now emerged as a powerful method for real time analysis of surfaces during thin film growth, and the development of a high data rate parallel instrument, described here, has removed a major obstacle to the achievement of this goal.
This work was supported by the National Science Foundation (Grant Nos. DMR-9202587 and DMR-9503210).

${ }^{1}$ H. A. Atwater and C. C. Ahn, Appl. Phys. Lett. 58, 269 (1991).

${ }^{2}$ C. C. Ahn, S. Nikzad, and H. A. Atwater, Mater. Res. Soc. Symp. Proc. 208, 157 (1991).

${ }^{3}$ S. Nikzad, C. C. Ahn, and H. A. Atwater, J. Vac. Sci. Technol. B 10, 762 (1992).

${ }^{4}$ S. Nikzad, S. S. Wong, C. C. Ahn, A. L. Smith, and H. A. Atwater, Appl. Phys. Lett. 63, 1414 (1993).

${ }^{5}$ H. A. Atwater, S. S. Wong, C. C. Ahn, S. Nikzad, and H. N. Frase, Surf. Sci. 298, 273 (1993).

${ }^{6}$ R. Homestead, O. L. Krivanek, R. Hoier, K. Marthinsen, and J. C. H. Spence, Ultramicroscopy 52, 454 (1993).

${ }^{7}$ S. Iwatani and K. Takayanagi, Jpn. J. Appl. Phys., Part 2 30, L1978 (1991).

${ }^{8}$ M. Zinke-Allmang and L. C. Feldman, Appl. Surf. Sci. 52, 357 (1991).

${ }^{9}$ Y. Horio, Y. Hashimoto, K. Shiba, and A. Ichimiya, Jpn. J. Appl. Phys., Part 1 34, 5869 (1995).

${ }^{10}$ B. Muller and M. Henzler, Rev. Sci. Instrum. 66, 5232 (1995). 